http://jmscr.igmpublication.org/home/ ISSN (e)-2347-176x ISSN (p) 2455-0450 crossref DOI: https://dx.doi.org/10.18535/jmscr/v7i9.37

\title{
A Study of Highly Sensitive C - Reactive Protein Level in Chronic Kidney Disease Patients of Age between 20-40 Years and its Correlation with Micro and Macro Vascular Complications
}

\author{
Authors
}

\section{Dr Yogendra Jamra ${ }^{1}$, Dr Shiv Shankar Badole ${ }^{2 *}$, Dr Archana Verma ${ }^{3}$, Dr Rajendra Uikey ${ }^{4}$, Dr Umesh Kumar Chandra ${ }^{5}$}

${ }^{1}$ MD Medicine, Associate Professor, Department of Medicine, MGM Medical College, Indore, MP, India

${ }^{2}$ MD Medicine, Senior Resident, Department of Medicine, MGM Medical College, Indore, MP, India ${ }^{3}$ DNB Neurology, Associate Professor, Department of Medicine, MGM Medical College, Indore, MP, India

${ }^{4,5}$ MD Medicine, Senior Resident, Department of Medicine, MGM Medical College, Indore, MP, India *Corresponding Author

\section{Dr Shiv Shankar Badole, MD Medicine}

Senior Resident, PG Boys Hostel, MGM Department of Medicine, MGM Medical College, Indore, MP, India

\begin{abstract}
Introduction: Chronic kidney disease (CKD) is worldwide a major public health problem, with increasing incidence, prevalence, high cost and poor outcomes. Highly sensitive CRP (hsCRP) has been introduced as a predictor of cardiovascular events in cardiovascular medicine. It has been noted that hsCRP can bind to damaged endothelial cells, activate the complement system, promote foam cell formation, aggregate lowdensity lipoprotein, and stimulate tissue factor production by monocytes. hsCRP can also induce adhesion molecules in endothelial cells and deposit along the walls of glomerular capillaries, suggesting that hsCRP may participate in the pathogenesis of glomerulosclerosis and atherosclerosis.

Materials and Methods: This cross section observational study was conducted in 104 patients of End Stage Renal Disease attending OPD of Department of Medicine, MGM Medical College and MY Hospital, Indore, MP, for conservative treatment from April 2017 to March 2018.

Results: In our study, the mean level of hsCRP was $17.58 \pm 8.5 \mathrm{mg} / \mathrm{dl}$. In $93.4 \%$ of patients hsCRP was raised above $5 \mathrm{mg} / \mathrm{dl}$ and in $46.2 \%$ of subjects, hsCRP was $>20 \mathrm{mg} / \mathrm{dl}$. Prevalence of Heart Failure, CVA, CAD, Retinopathy, and Neuropathy were $18.3 \%, 3.8 \%, 2.9 \%, 26.9 \%$, and $5.7 \%$ patients respectively. There was no significant correlation between hsCRP level and heart failure, CVA, CAD, and Retinopathy, and observed $p$ values were $0.994,0.476,0.246$, and 0.287 respectively.

Conclusions: The present study shows excess inflammation and oxidative stress in the CKD patients, in form of raised hsCRP in 93.4\% of patients. As our aim was to find out any correlation between the serum hsCRP level, and micro and macro vascular complications in CKD patients but significant correlation of fore-mentioned complications with hSCRP level could not be obtained in our study.

Keywords: Chronic Kidney Disease, hsCRP, macro and micro vascular complication.
\end{abstract}

\section{Introduction}

Chronic kidney disease (CKD) is a worldwide major public health problem with increasing incidence, prevalence, high cost and poor outcomes $^{[1]}$. It encompasses a spectrum of different pathophysiologic processes associated 
with abnormal kidney function and a progressive decline in glomerular filtration rate (GFR). Most of the population study of CKD has focused on the prevalence of CKD. The most appropriate source, till now for determining the prevalence of CKD in the population of an entire country has been the National Health and Nutrition Examination Surveys (NHANES) in the United States. NHANES is a series of surveys encompassing interviews and physical examinations on a nationally representative sample of participants and it is sponsored by the Centers for Disease Control and Prevention (CDC). The second series of NHANES (NHANES II) was conducted from 1976 to 1980; and the latest series was launched in 1999 as a continuous survey.

In Indian perspective, an accurate estimate of the number of patients on the Indian subcontinent who have chronic kidney disease (CKD) or need renal replacement therapy (RRT) is not available due to lack of nationwide registry data. $\mathrm{Mani}^{[2]}$ reported a prevalence of CKD of $1.1 \%$ among a rural population of 25,000 who were subjects of a universal screening program in which serum creatinine level was measured only in those with hypertension or proteinuria. Agarwal et $\mathrm{al}^{[3]}$ screened 4700 adults in an urban community and found a point prevalence of 7852 per million individuals with a serum creatinine level greater than $1.8 \mathrm{mg} / \mathrm{dl}$, however these figures must be interpreted with caution because of the wide variations in the definition of $\mathrm{CKD}$, methodology and sampled population.

Highly sensitive C - reactive protein (hsCRP) was discovered in 1930 by William Tillett and Thomas Francis, investigators at the Rockefeller University. They found it could be isolated from the blood of patients with a specific type of pneumonia. Later it was discovered that elevated hsCRP-levels can be measured in blood in response to inflammation. Elevated plasma hsCRP level, the prototypic marker of inflammation, has been shown to be strongly predictive of an increased risk of future myocardial infarction and predicts mortality in apparently healthy people as well as in patients with established coronary artery disease. hsCRP has been introduced as a predictor of cardiovascular events in cardiovascular medicine ${ }^{[4]}$. It has been noted that hsCRP can bind to damaged endothelial cells, activate the complement system, promote foam cell formation, aggregate low-density lipoprotein, and stimulate tissue factor production by monocytes ${ }^{[5-8]}$. hsCRP can also induce adhesion molecules in endothelial cells and deposit along the walls of glomerular capillaries, suggesting that hsCRP may participate in the pathogenesis of glomerulosclerosis and atherosclerosis ${ }^{[9]}$. Irrespective of the causes, most CKD presentations share common histological presentations of glomerulosclerosis, tubulointerstitial fibrosis, and vascular sclerosis ${ }^{[10]}$. Studies have identified inflammation as an important pathogenic factor in renal injury. Inflammation mediates the processes of monocyte influx, proliferation of macrophages and matrix expansion, and results in glomerulosclerosis and tubulointerstitial injury ${ }^{[11-13]}$ which may further exacerbate kidney injuries. Inflammation may stimulate glomerular cells to increase production and reduce degradation of extracellular matrix protein, leading to glomerular hypertension, tubulointerstitial fibrosis, and renal scarring ${ }^{[14]}$. Accumulating 10 clinical evidences has demonstrated that inflammation is one of the major causes of poor outcome in patients with renal failure.

The new clinical meaning of hsCRP in ESRD patients is that of an index that reflects their overall health state as determined by several conditions. It shows the grade of their health condition mainly by renal insufficiency and its complications. The accurate assessment of hsCRP gives an estimation of the overall health status during the period of the measurement. A high value indicates an unfavorable condition aggravated by renal insufficiency and its micro and macro vascular complications, while a lower one should show a relatively good condition of their health. 


\section{Materials and Methods}

This cross section observational study was conducted in 104 patients of End Stage Renal Disease attending OPD of Department of Medicine, MGM Medical College and MY Hospital, Indore, MP, for conservative treatment from April 2017 to March 2018. Patients were grouped into the stages according to the KDOQI stages of kidney disease depending on GFR in $\mathrm{ml} / \mathrm{min} / 1.73 \mathrm{~m}^{2}$ of body surface area.

\section{Inclusion Criteria}

Males and females in age group of 20-40 years who were diagnosed as CKD and on conservative treatment, pre dialysis and End-stage renal disease (ESRD) patients on dialysis, attending Department of Medicine, M Y Hospital Indore in specified time period from April 2017 to March 2018 were taken as cases.

\section{Exclusion Criteria}

Patients with

- Acute or chronic infections,

- Acute renal failure,

- Acute tubular necrosis,

- Previous coronary vascular disease, peripheral artery disease and cerebrovascular disease,

- Previous history of heart failure,

- Diseases of the immune system such as lupus,

- Systemic inflammatory diseases e.g. rheumatoid arthritis, inflammatory bowel disease, ankylosing spondylitis, psoriasis etc,

- Chronic alcoholic, smoker, and tobacco chewer,

- Patients of burn, trauma, or who had undergone a recent surgery.

\section{Ethic Statement}

After the study protocol approved by the Institutional Review Board, Informed consents was obtained in written form from patients and then all clinical investigation were conducted.

\section{Data Collection}

Questionnaires were administered to the study subjects by the researchers to obtain demographic information such as age, gender, and clinical history such as history of renal symptoms, common etiologies such as hypertension, diabetes mellitus, retroviral disease, hemoglobinopathies, obstructive uropathy, connective tissue disease and previous or family history of renal disease.

Study subjects were physically examined. Weight was measured using a weighing scale with subjects wearing light clothing. Body mass index $\left(\mathrm{kg} / \mathrm{m}^{2}\right)$ was calculated using the formula; Weight $(\mathrm{kg}) /$ Height in $\mathrm{m}^{2}$. The etiology of renal disease in CKD subjects were determined by the researchers using the information obtained from administered questionnaires, physical examination findings and investigations in patient's clinical folders as follow:

Diabetic Nephropathy: A diagnosis of diabetes mellitus, features of other micro vascular complications, presence of hypertension, significant proteinuria and presence of large or normal sized kidneys on ultrasound in the absence of other possible etiological factors.

Hypertensive Nephropathy: A history of long standing hypertension, presence of features of long standing hypertension such as hypertensive retinopathy, thickened arterial wall, locomotor brachii and loud aortic component of second heart sound.

Sickle Cell Nephropathy: Sickle cell disease patient with or without nephrotic range proteinuria, normal sized or enlarged kidneys on ultrasound, absence of other etiological factors like DM and hypertension.

\section{Autosomal Dominant Polycystic Kidney}

Disease: Presence of $\geq 3$ cysts, which may be unilateral or bilateral in patients aged between 1539 years, $\geq 2$ cysts in each kidney for patients aged 40-59 and $\geq 4$ cysts in each kidney for patients aged $\geq 60$ and positive family history.

Chronic Glomerulonephritis: Past history of acute glomerulonephritis or nephrotic syndrome, active urinary sediments, significant proteinuria, bilaterally shrunken kidneys, features of long standing hypertension, DM or other etiological factors. 
Obstructive Uropathy: Presence of clinical features of urinary obstruction, dilated pelvicalyceal system, normal or enlarged kidneys on ultrasound in the absence of other etiological factors.

Micro-vascular complications were included as neuropathy, retinopathy and macro-vascular complications were included as heart failure, coronary artery disease and cerebrovascular disease.

Blood sampling was performed between 8 and 10 a.m. after an overnight fasting. Laboratory parameters included $\mathrm{CBC}$, kidney function tests, fasting glucose, lipid profile, and serum hsCRP. hsCRP level were estimated by using standard method on the same day of collection by nephelometry method. The cohort of patient was followed for 6 months after initial measurement of hsCRP levels.

Results were presented in tabular form. Discrete variables were presented as frequency and percentages. Continuous data were expressed as mean standard deviation (SD), and the Student's ttest and chi square test were used to analyze continuous variables and categorical data, respectively. Correlations between continuous variables were determined using Pearson's test. A multivariable logistic regression analysis was used to identify independent factors associated with GFR. Univariate analysis was used in description of demographic characteristics of the study population. Significant variables from the univariate analysis were further tested in the multivariate regression analysis. Calculations were performed with SPSS 10.0 software. $\mathrm{p}$ value $<0.05$ was considered significant.

\section{Results}

In this study, hsCRP level of most of the patients was raised above the baseline. The mean level of hsCRP was $17.58 \pm 8.5 \mathrm{mg} / \mathrm{dl}$. As shown in table 1 , in $93.4 \%$ of patients hsCRP was raised above 5 $\mathrm{mg} / \mathrm{dl}$ and in $46.2 \%$ of patients hsCRP was $>20$ $\mathrm{mg} / \mathrm{dl}$.
As shown in table 2, after six months of follow up, out of 104 patients, 19(18.3\%) developed heart failure, 4(3.8\%) patients developed CVA, and $3(2.9 \%)$ patients developed coronary artery disease. As micro vascular complication, retinopathy was present in 28(26.9\%) and neuropathy was present in $6(5.7 \%)$ patients on clinical examination.

As shown in table 3, heart failure was present in $19(18.3 \%)$ out of 104 patients, and there was no significant correlation between hsCRP level and heart failure (' $\mathrm{t}$ ' value $0.083, \mathrm{df}=3$, p value 0.994 ) was found. As shown in table 4, correlation between CVA and level of hsCRP was not significant ( $p$ value $=0.476$ ). As shown in table 5, correlation between CAD and level of hsCRP was not significant (' $\mathrm{t}$ ' value $=4.145, \mathrm{df}=3, \mathrm{p}$ value $=$ 0.246). As shown in table 6 , correlation between occurrence of retinopathy and level of hsCRP was not significant (' $\mathrm{t}$ ' value $=3.777, \mathrm{df}=3, \mathrm{p}$ value $=$ 0.287).

All observed values show that there is no significant correlation between hsCRP level in CKD patients and their micro and macro vascular complications.

Table 1: Distribution of patients according hsCRP level

\begin{tabular}{|l|c|c|}
\hline hsCRP Level (in mg/dl) & Patients & Percent \\
\hline $0-5$ & 7 & 6.7 \\
\hline $6-10$ & 22 & 21.2 \\
\hline $11-20$ & 27 & 26 \\
\hline$>20$ & 48 & 46.2 \\
\hline Total & 104 & 100 \\
\hline
\end{tabular}

Table 2: Distribution of macro and micro vascular complications in CKD patients

\begin{tabular}{|l|c|c|c|c|c|}
\hline \multirow{2}{*}{$\begin{array}{l}\text { Compli } \\
\text { cations }\end{array}$} & \multicolumn{2}{|c|}{ Macro vascular } & \multicolumn{2}{c|}{ Micro vascular } \\
\cline { 2 - 6 } & $\begin{array}{c}\text { Heart } \\
\text { Failure( } \\
\text { \%) }\end{array}$ & $\begin{array}{c}\text { CVA( } \\
\text { \%) }\end{array}$ & $\begin{array}{c}\text { CAD( } \\
\text { \%) }\end{array}$ & $\begin{array}{c}\text { Retinopat } \\
\text { hy(\%) }\end{array}$ & $\begin{array}{c}\text { Neuropat } \\
\text { hy(\%) }\end{array}$ \\
\hline Yes & $19(18.3)$ & $4(3.8)$ & $3(2.9)$ & $28(26.9)$ & $6(5.7)$ \\
\hline No & $85(81.7)$ & $\begin{array}{c}100(9 \\
6.2)\end{array}$ & $\begin{array}{c}101(9 \\
7.1)\end{array}$ & $76(73.1)$ & $98(94.3)$ \\
\hline
\end{tabular}


Table 3: Association of hsCRP level with occurrence of heart failure in patients on follow up

\begin{tabular}{|l|c|c|c|c|c|}
\hline \multirow{2}{*}{$\begin{array}{l}\text { hsCRP } \\
(\mathbf{m g} / \mathbf{d l})\end{array}$} & \multicolumn{2}{|c|}{$\begin{array}{c}\text { Heart } \\
\text { Failure }\end{array}$} & Total & 't' value & P value \\
\cline { 2 - 4 } & Yes & No & & & \\
\hline $\mathbf{0 - 5}$ & 1 & 6 & 7 & \multirow{2}{*}{0.083,} & \multirow{2}{*}{0.994} \\
\hline $\mathbf{6 - 1 0}$ & 4 & 18 & 22 & \multirow{2}{*}{$\mathrm{df}=3$} & \\
\hline $\mathbf{1 1 - 2 0}$ & 5 & 22 & 27 & \\
\cline { 1 - 4 } $\boldsymbol{> 2 0}$ & 9 & 39 & 48 & & \\
\hline Total & 19 & 85 & 104 & & \\
\hline
\end{tabular}

Table 4: Association of hsCRP level with occurrence of CVA in patients on follow up

\begin{tabular}{|c|c|c|c|c|c|}
\hline \multirow{2}{*}{$\begin{array}{l}\text { hsCRP } \\
\text { (mg/dl) }\end{array}$} & \multicolumn{2}{|c|}{ CVA } & \multirow[t]{2}{*}{ Total } & \multirow[t]{2}{*}{ 't' value } & \multirow[t]{2}{*}{ P value } \\
\hline & Yes & No & & & \\
\hline $0-5$ & 1 & 6 & 7 & \multirow{5}{*}{$\begin{array}{c}2.47 \\
\mathrm{df}=37\end{array}$} & \multirow{5}{*}{0.476} \\
\hline 6-10 & 1 & 21 & 22 & & \\
\hline $11-20$ & 1 & 26 & 27 & & \\
\hline$>20$ & 1 & 47 & 48 & & \\
\hline Total & 4 & 100 & 104 & & \\
\hline
\end{tabular}

Table 5: Association of hsCRP level with occurrence of CAD in patients on follow up

\begin{tabular}{|l|c|c|c|c|c|}
\hline \multirow{2}{*}{$\begin{array}{l}\text { hsCRP } \\
(\mathbf{m g} / \mathbf{d l})\end{array}$} & \multicolumn{2}{|c|}{ CAD } & Total & 't' value & P value \\
\cline { 2 - 4 } $\mathbf{0 - 5}$ & Yes & No & & & \\
\hline $\mathbf{6 - 1 0}$ & 0 & 7 & 7 & \multirow{3}{*}{$\begin{array}{c}\text { 4.145, } \\
\text { df=3 }\end{array}$} & 0.246 \\
\cline { 1 - 4 } $\mathbf{1 1 - 2 0}$ & 2 & 20 & 22 & & \\
\hline$>\mathbf{2 0}$ & 0 & 27 & 27 & & \\
\hline Total & 3 & 47 & 48 & & \\
\hline
\end{tabular}

Table 6: Association of hsCRP level with occurrence of retinopathy in patients on follow up

\begin{tabular}{|c|c|c|c|c|c|}
\hline \multirow{2}{*}{$\begin{array}{l}\text { hsCRP } \\
\text { (mg/dl) }\end{array}$} & \multicolumn{2}{|c|}{ Retinopathy } & \multirow[t]{2}{*}{ Total } & \multirow[t]{2}{*}{ 't' value } & \multirow[t]{2}{*}{$P$ value } \\
\hline & Yes & No & & & \\
\hline $0-5$ & 1 & 6 & 7 & \multirow{5}{*}{$\begin{array}{c}3.777 \\
\mathrm{df}=3\end{array}$} & \multirow{5}{*}{0.287} \\
\hline 6-10 & 5 & 17 & 22 & & \\
\hline 11-20 & 11 & 16 & 27 & & \\
\hline$>20$ & 11 & 37 & 48 & & \\
\hline Total & 28 & 76 & 104 & & \\
\hline
\end{tabular}

\section{Discussion}

The present study shows excess inflammation and oxidative stress in the CKD patients, as hsCRP was raised in $93.4 \%$ of patients above $5 \mathrm{mg} / \mathrm{dl}$. Our study enrolled 104 patients, of which 36 were females and 68 were male. Patterns in the incidence of kidney disease across gender are generally consistent, with higher rates occurring in men than in women. Similarly, men are reported to have greater rates of progression of non diabetic CKD for some specific types of kidney disease, especially compared with premenopausal women. US Renal Data System ${ }^{[15]}$ has also reported the incidence rates for end-stage renal disease (ESRD) approximately 60\% higher among men than women.

The prevalence of CKD increases with age and is reported to be as high as $56 \%$ in people aged 75 years or older ${ }^{[16]}$. Longitudinal studies of subjects without kidney disease have demonstrated a decline in GFR with increasing age in some but not all subjects, which implies that nephron loss may be regarded as part of normal aging ${ }^{[17]}$. However in our study we included only patients of age between 20 to 40 years so that age related effects could not be studied. Beside that our study is unique as we could not find any past study in literature considering young adults with CKD.

Sumanth kumar et al ${ }^{[18]}$ found the levels of hsCRP were high in patients with chronic kidney disease as compared to the controls. The mean and standard deviation (SD) of hsCRP in the total cases was $26.08 \pm 5.73$, as compared to the control group which was $0.83 \pm 0.15$. Sanjin racki et al ${ }^{[19]}$ in their study had $65.5 \%$ patients with hsCRP $>3 \mathrm{mg} / \mathrm{dl}$, in which 111 (47.9\%) patients had hsCRP $>10.0$ mg/L. A study by Fred S. Apple had found elevated hsCRP in $46 \%$ of the patients. Zimmermann $\mathbf{J}$ et al found Serum CRP elevated (more than 8 ) in $46 \%$ of subjects. In a study by stenvinkel $\mathrm{P}$ et al, $32 \%$ of all patients had elevated CRP levels.

The aim of our study was to assess the micro and macro vascular complications in 6 month follow up and to assess the correlation, if any, with the hsCRP levels. We found that on 6 month follow up $19(18.3 \%)$ patients had heart failure, 4 (3.8\%) patients had CVA and 3(2.9\%) patients had CAD. However, we could not find any significant correlations of fore-mentioned complications with the hsCRP level in our study. In the study by Diana Jalal et al after 4 years of follow-up, 204 (6.4\%) participants experienced a major cardiovascular event. High hsCRP level and CKD at baseline were associated with a greater risk of 
vascular events. Compared to patients with low hsCRP/non-CKD, the adjusted hazard ratio (95\% CI) for vascular events was $1.93(1.45 ; 2.89)$ for high hsCRP/CKD. Zimmermann $\mathrm{J}$ et al followed patients of CKD for 2 years. During follow-up, 72 patients $(25.7 \%)$ died, mostly due to cardiovascular events (58\%). Overall mortality and cardiovascular mortality were significantly higher in patients with elevated CRP (31\% vs. $16 \%, \mathrm{P}<0.0001$, and $23 \% 77$ vs. $5 \%, \mathrm{P}<0.0001$, respectively). Yeun JY et al followed hemodialysis patients during a 34-month followup period and found that the group with the greatest CRP level (>11.5 micro $\mathrm{g} / \mathrm{ml}$ ) had the lowest survival. Probable cause of poor correlation between cardiovascular risk factors and hsCRP in our study was short duration and short follow up.

The association between inflammatory markers and cardiovascular events, coronary artery disease and its complications occur with high frequency in patients with ESRD; and substantially is contributing to cardiovascular morbidity and mortality in this population.

However, serum hsCRP elevation is not specific but may change due to several inflammatory or non-inflammatory responses. In our study a significant association may have been missed due to small sample size in the present study. A weakness in the present study is its cross section observational natures for short duration as well as relatively small sample size. In an observational study, it is possible to demonstrate associations between $\mathrm{CKD}$ and the presence of increased oxidative stress and inflammation, but not to determine causal relationships. Additionally, because of the relatively small sample size, there may be relationships between clinical parameters (such as etiology of renal disease, gender, race, age, nutritional status, and conventional cardiovascular risk factors), inflammation, and oxidative stress in the CKD population, which could not be studied in detail.

\section{Conclusions}

The present study shows excess inflammation and oxidative stress in CKD patients, as hsCRP was raised in $93.4 \%$ of patients. Our aim was to find out any correlation between the serum hsCRP levels and micro and macro vascular complications in CKD patients, but we could not find any such significant correlation.

\section{Disclosure}

Funding: No funding sources

Conflict of interest: Not declared

Ethical approval: The study was approved by the institutional ethics committee.

\section{References}

1. U.S. Renal Data System: 2009 Annual data report. Section A: incidence of reported ESRD. Available at: http://www.usrds.org/2009/ref/A_Ref_09. pdf. Accessed December 17, 2010.

2. Mani MK. The management of end-stage renal disease in India. Artif Organs. 1998;22:182-186.

3. Agarwal SK, Dash SC, Irshad M, et al. Prevalence of chronic renal failure in adults in Delhi, India. Nephrol Dial Transplant. 2005;20:1638-1642.

4. Chiang CE, Wang TD, Li YH, et al. 2010 guidelines of the Taiwan Society of Cardiology for the management of hypertension. J Formos Med Assoc 2010;109:740-73.

5. Cermak J, Key NS, Bach RR, et al. Creactive protein induces human peripheral blood monocytes to synthesize tissue factor. Blood 1993;82:513-20.

6. Pepys MB, Rowe IF, Baltz ML. C-reactive protein: binding to lipidsand lipoproteins. Int Rev ExpPathol 1985;27:83-111.

7. Nakagomi A, Freedman SB, Geczy CL. Interferon-gamma and lipopolysaccharide potentiate monocyte tissue factor induction by $\mathrm{C}$ reactive protein: relationship with 
age, sex, and hormone replacement treatment. Circulation 2000;101:1785-91.

8. Nakahara C, Kanemoto K, Saito N, et al. $\mathrm{C}$-reactive protein frequently localizes in the kidney in glomerular diseases. Clin Nephrol 2001;55:365-70.

9. Coresh J, Wei GL, McQuillan G, et al. Prevalence of high blood pressure and elevated serum creatinine level in the United States: findings from the third National Health and Nutrition Examination Survey (1988-1994). Arch Intern Med 2001;161: 1207-16.

10. Serum C-reactive protein levels in predialysis chronic kidney disease patients in southern Nigeria Oluseyi A Adejumo, 2016.

11. Rifkin DE, Sarnak MJ (2009) Does inflammation fuel the fire in CKD? Am J Kidney Dis 53: 572-575.

12. Qian Y, Feldman E, Pennathur S, Kretzler M, Brosius FC 3rd (2008) From fibrosis to sclerosis: mechanisms of glomerulosclerosis in diabetic nephropathy. Diabetes 57: 1439-1445.

13. Dalla Vestra M, Mussap M, Gallina P, Bruseghin M, Cernigoi AM, et al. (2005) Acute-phase markers of inflammation and glomerular structure in patients with type 2 diabetes. J Am Soc Nephrol 16 suppl $1: 78-82$.

14. Navarro JF, Milena FJ, Mora C, Leon C, Garcia J Renal proinflammatory cytokine gene expression in diabetic nephropathy: 88 effect of angiotensin- converting enzyme inhibition and pentoxifylline administration. Am J Nephrol 26: 562570.

15. USRDS, annual data report: atlas of end stage renal disease in the United States. Bethesda, Md: National Institutes of Health, National Institute of Diabetes and Digestive and Kidney Diseases; 2009.
16. Roderick PJ, Atkins RJ, Smeeth L, et al. CKD and mortality risk in older people: a community-based population study in the United Kingdom. Am J Kidney Dis. 2009;53:950-960.

17. Lindeman RD, Tobin J, Shock NW. Longitudinal studies on the rate of decline in renal function with age. $\mathrm{J}$ Am Ger Soc. 1985;33:278-285.

18. Dr. Sumanth kumar B, Dr. Shobharani. B, Comparative Study of hsCRP in Chronic Kidney Disease,2015.

19. Sanjin Rački, C reactive Protein Is a Strong Predictor of Mortality in Hemodialysis Patients, 2009. 